\title{
Hipólito Unanue en la numismática peruana
}

\author{
Ricardo Álvarez ${ }^{1,2,3}$
}

Resumen

Palabras clave

\begin{abstract}
La Numismática es una rama de la Historia que estudia a las monedas, medallas, condecoraciones, papel moneda y sucedáneos, a través de los cuales podemos conocer los hechos históricos de las naciones. Nuestra patria es, sin duda, una de las naciones latinoamericanas con mayor tradición en este tema. Por ello, ha sido frecuente que algunos de nuestros personajes más ilustres hallan sido recordados a través de estos pequeños objetos. Don José Hipólito Unanue y Pavón es, junto a Cayetano Heredia y Daniel Carrión, uno de los más genuinos representantes de la Medicina nacional. Sin embargo, a diferencia de los anteriores incursionó en la política y en otras ciencias, lo que le dio una dimensión que trasciende más allá del ámbito médico. En ese sentido, la numismática ha contribuido a difundir su imagen en los lugares más apartados del mundo. Su rostro ha sido conocido por hombres que no saben de nuestra cultura, ni siquiera de nuestro idioma, y sin embargo son capaces de identificarlo en un trozo de papel o en un disco de metal. A pesar de ello, ninguna de las investigaciones sobre Unanue se refirió a su presencia en la numismática, carencia que intentamos subsanar en este artículo.
\end{abstract}

Perú, historia de la medicina; Unanue, Hipólito; numismática.

\section{Hipolito Unanue in the Peruvian numismatics} Abstract

Numismatics is the branch of History that studies coins, medals, decorations, paper money and related subjects through which we learn on the historic events of nations. Our country is doubtless one of the Latin American nations with the greatest traditions on the subject and some of our most illustrious figures are recalled through these small objects. Jose Hipolito Unanue is, along with Cayetano Heredia and Daniel Carrion, one of the most genuine representatives of the nation's medical tradition. However, unlike the others, he was involved in politics and other sciences, giving him a dimension beyond the medical sphere. In this respect, numismatics has contributed to spread his image throughout the most remote parts of the world, allowing his face to be known by people who know nothing of our culture or even our language; yet, they can recognize him on a piece of paper or a metal disc. In spite of this, none of the research on Unanue has referred to his presence in numismatics, a gap that we hope to close by this article.

Keywords: Peru, history of medicine; Unanue, Hipolito; numismatics.

\footnotetext{
1 Médico Patólogo Clínico del Instituto Nacional Materno Perinatal. Lima, Perú.

2 Miembro titular de la Sociedad Peruana de Patología Clínica. Lima, Perú.

3 Past - Presidente de la Sociedad Numismática del Perú. Lima, Perú.
}

\section{Introducción}

El Perú fue una de las naciones del Nuevo Mundo donde se cultivó más asiduamente la acuñación de las monedas y medallas, pues al ser la posesión hispana más importante en la América Meridional, en ella se fundaron las Casas de Moneda de Lima y Potosí.

Prueba de ello son las bellas medallas acuñadas para jurar la fidelidad a los Reyes de España, cuya perfección no tiene nada que envidiar a sus contemporáneas fabricadas en Europa. Del mismo modo, son representativas las magníficas balotas utilizadas para calificar los exámenes de graduación en la Real Universidad de San Marcos.

Durante la Colonia, el ritmo de fabricación monetaria, aunque fluctuante, fue suficiente para atender las necesidades de la población y del gobierno. Sin embargo, el advenimiento de las luchas por la emancipación generó una seria disminución en la provisión de los metales necesarios para las diversas acuñaciones. En ese momento crucial, Hipólito Unanue, quien ejercía el cargo de Ministro de Hacienda, tomó las medidas que permitieron la fabricación de las primeras monedas del Perú independiente y de la primera condecoración de nuestra historia, la Orden del Sol del Perú, instaurada por José de San Martín. 
En los primeros años de la República, la Casa de Moneda de Lima siguió la suerte del país, es decir, entró en una etapa de decadencia. Recién en 1856, el gobierno de Ramón Castilla contrató al grabador inglés Robert Briten, quien introdujo nuevas técnicas que perfeccionaron la acuñación de monedas y medallas.

En 1874, apareció la primera medalla peruana, hasta hoy conocida, relacionada a nuestra Medicina; se trató de un pequeño y muy raro ejemplar mandado a acuñar por los estudiantes de San Fernando para celebrar las Fiestas Patrias de ese año.

Esta temática se hizo recurrente en nuestra medallística. Así, en 1899, el talla limeño Juan Francisco Rodríguez grabó la medalla que conmemoró el inicio de la construcción del actual local de San Fernando, en cuyo anverso se erguía el busto del Presidente Nicolás de Piérola, quien autorizó el presupuesto para esta obra y colocó solemnemente su primera piedra.

El 6 de septiembre de 1903, al inaugurarse este local, los principales invitados fueron obsequiados con unas hermosas medallas, las primeras en las que apareció la fachada de San Fernando, y que fueron diseñadas por el artista nacional Guillermo Gonzáles Moreno.

Posteriormente, el grabador huancavelicano don Armando F. Pareja Landeo talló varias medallas relacionadas a nuestra Medicina, entre ellas la del bicentenario del natalicio de Hipólito Unanue (1955), la del primer centenario de la fundación de la Facultad de Medicina de San Fernando (1956) y la del primer centenario del nacimiento de Daniel Carrión (1957).

Durante el gobierno de Manuel A. Odría se contrató al eximio tallador francés Raymond Pelletier, de cuyas manos salieron los diseños de las condecoraciones de las Órdenes de Hipólito Unanue (1955) y Daniel Alcides Carrión (1957).

Desde la segunda mitad del siglo XX, la acuñación de medallas relacionadas a la Medicina peruana se hizo cada vez menos frecuente. Sin embargo, esta tradición fue conservada por la Universidad Peruana Cayetano Heredia, que hizo una costumbre celebrar cada quinquenio de su fundación con una medalla alusiva, además de hacer lo propio en homenaje a su primer Rector Honorio Delgado Espinosa, su primer Vicerrector Oscar Soto y su primer Decano de la Facultad de Medicina Alberto Hurtado Abadía.

\section{El recuerdo de Unanue en nuestra numismática}

El recuerdo de los grandes hombres se vuelve imperecedero a través de sus obras. Sin embargo, el inexorable paso del tiempo hace que sus méritos se tornen borrosos o simplemente se pierdan por completo. Es aquí donde la Numismática cumple un rol sorprendentemente importante que trasciende al tiempo, la geografía y las generaciones.

Hoy en día, la mayoría de los peruanos conocemos la obra de Unanue, pero esto no está garantizado indefinidamente, sobre todo en el contexto de un mundo globalizado que privilegia la imagen por sobre la lectura.

En el futuro, es probable que los libros que hablen sobre Unanue queden relegados en viejos estantes, mientras que las medallas o las imágenes de ellas generen, cada vez con más frecuencia, una cierta curiosidad en el neófito, cumpliendo con su cometido de fijar el recuerdo de este ilustre médico.

Con el fin de sistematizar la exposición de las piezas numismáticas alusivas a Unanue, las hemos ordenado en tres grupos: medallas, condecoraciones y papel moneda, y será en tal secuencia como las presentaremos a continuación.

\section{MEDALLAS}

\section{$5^{\circ}$ Congreso Médico Latinoamericano y $6^{\circ}$ Panamericano de Medicina}

La primera medalla alusiva a Unanue fue grabada en 1913, es decir, ochenta años después de su muerte. Esta se acuñó por encargo del comité organizador del $5^{\circ}$ Congreso Latinoamericano y $6^{\circ}$ Panamericano de Medicina, ambos realizados en la ciudad de Lima durante el mes de noviembre de dicho año.

Aquel comité, presidido por el doctor Ernesto Odriozola, obsequió gran parte de los ejemplares de esta medalla a los congresales que asistieron a la ceremonia inaugural de dichos eventos, garantizando con ello que la imagen de Unanue se difundiera por todos los rincones del continente americano.

La medalla fue fabricada en la Carlos F. Southwell \& Company, empresa que fundó en Lima este súbdito británico en 1884. Su diseño fue encomendado al grabador nacional Edmundo Callirgos, quien plasmó en el anverso el busto de Unanue en perfil derecho $3 / 4$. 

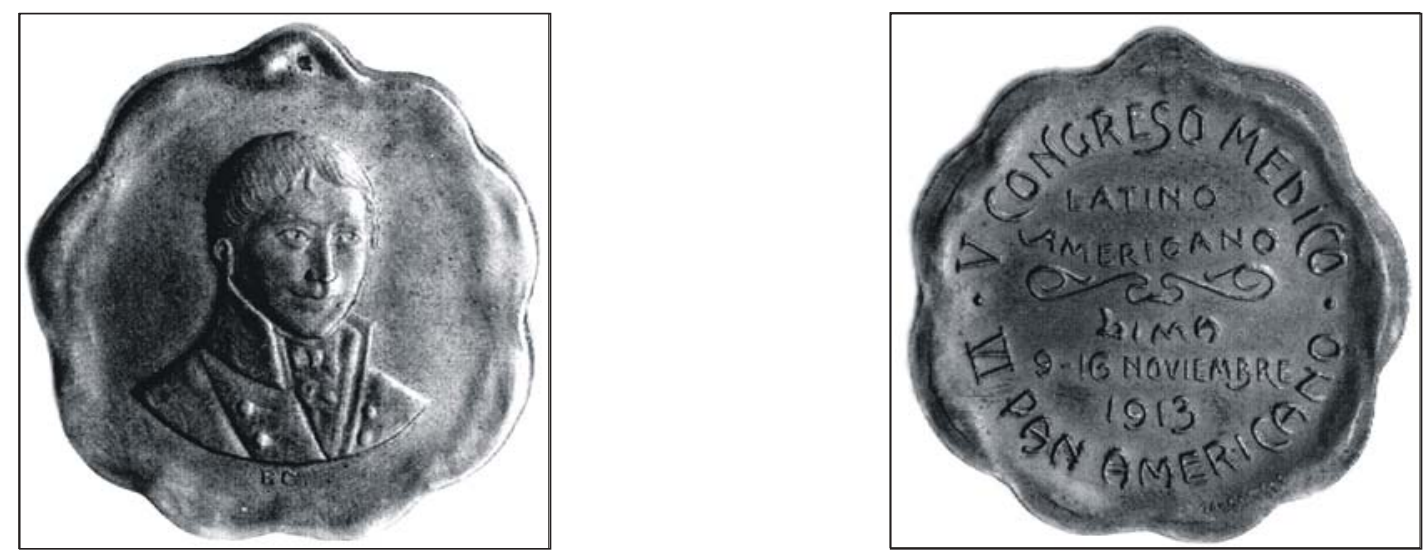

Figura 1. Anverso y reverso de la medalla por el $5^{\circ}$ Congreso Médico Latinoamericano y $6^{\circ}$ Congreso Panamericano de Medicina efectuado en la ciudad de Lima en noviembre de 1913.

El reverso tenía la inscripción " $V$ CONGRESO MÉDICOLATINO AMERICANO - VI PANAMERICANO - LIMA 9-16 NOVIEMBRE 1913” y, cerca del canto, en caracteres muy pequeños, la palabra "SOUTHWELL" $\left({ }^{1}\right)$. El borde ondulado de esta medalla es una peculiaridad poco común en las piezas peruanas de la República (Figura 1).

\section{Bicentenario del nacimiento de Hipólito Unanue}

En octubre de 1954, el doctor Carlos Enrique Paz Soldán propuso al Decano de San Fernando la organización de las celebraciones por el bicentenario del natalicio de Hipólito Unanue, que se cumpliría el 13 de agosto del año siguiente. En vista de ello, se designó a una comisión integrada por los doctores Honorio Delgado, Carlos Krumdieck y el propio Paz Soldán; quienes solicitaron al Congreso de la República la dación de una ley que le diera dimensión nacional a la efemérides $\left({ }^{2}\right)$.

Ello fue acogido por el Diputado por Junín, don Augusto Peñaloza, quien presentó un proyecto que se convirtió en la Ley $\mathrm{N}^{\circ} 12343$, promulgada el 10 de junio de 1955, en virtud de la cual se declaró agosto de aquel año como el 'Mes de Unanue y de la Cultura Peruana' $\left({ }^{2}\right)$.

El 10 de julio de 1955, la Resolución Suprema $\mathrm{N}^{\circ} 107$ nombró la comisión organizadora de las celebraciones, que, encabezada por el Director de Educación Artística y Extensión Cultural del Ministerio de Educación, estuvo integrada por los representantes del Centro de Estudios Histórico Militares, la Asociación Nacional de Escritores y Artistas, la revista 'Mercurio Peruano', la familia de Unanue y la Facultad de San Fernando. Este último puesto lo ocupó el doctor Paz Soldán $\left({ }^{2}\right)$.

La comisión llevó a cabo diversas actividades, tales como conferencias radiales, conciertos, colocación de sendas placas celebratorias en las avenidas bautizadas con el nombre de Unanue, ubicadas en los distritos limeños de La Victoria y San Isidro, e incluso gestionó que el futuro Hospital del Seguro Social del Empleado de Lima, que por entonces estaba en plena construcción, se denominara con el nombre del prócer, aunque finalmente el Hospital Regional de Tacna, inaugurado ese mismo año, fue el que recibió el nombre de nuestro personaje $\left(^{2}\right)$.

A pedido de la comisión, el Ministerio de Educación Pública aprobó la acuñación de una medalla conmemorativa que fue fabricada en la Casa Nacional de Moneda $\left({ }^{1}\right)$, siendo grabada por Armando Pareja, quien plasmó en su anverso un busto estilizado de Unanue, rodeado por la inscripción "HIPÓLITO UNANUE”. En el reverso buriló la expresión "BICENTENARIO DE SU NACIMIENTO. $13 \mathrm{DE}$ AGOSTO 1755-1955. MINISTERIO DE EDUCACIÓN PÚBLICA" (Figura 2).

\section{Respetable Logia Simbólica 'Hipólito Unanue' N 65}

La mayoría de historiadores de la masonería peruana concuerda en que Unanue perteneció a ella; 
por tanto, siguiendo una antigua tradición masónica, solo era cuestión de tiempo para que alguna de las nuevas logias tomara su nombre. Así, el 24 de febrero de 1964, se instaló en la ciudad de Lima la Respetable Logia Simbólica 'Hipólito Unanue', a la que se asignó el número 65.

Las logias han acostumbrado acuñar medallas que son utilizadas por sus miembros como insignias, las cuales son portadas en sus reuniones rituales denominadas 'Tenidas'. La logia 'Hipólito Unanue' no fue la excepción, y en varias ocasiones encargó la fabricación de diferentes tipos de medallas (Figuras 3 y 4). Curiosamente, en ninguno de los modelos figura la efigie de Unanue.

\section{Fundación Instituto Hipólito Unanue}

El 27 de febrero de 1967, la Asociación de Laboratorios Farmacéuticos del Perú (Alafarpe) estableció la Fundación Instituto Hipólito Unanue para promover la enseñanza, investigación y perfeccionamiento de las disciplinas médicas.

Esta entidad mandó a fabricar una medalla institucional, en cuyo anverso aparece el busto de nuestro personaje, en perfil derecho $3 / 4$, rodeado por la inscripción circular "HIPÓLITO UNANUE"; el reverso solo contiene la expresión "FUNDACIÓN INSTITUTO HIPÓLITO UNANUE” (Figura 5). Su grabador es desconocido.

La Tabla 1 resume las características técnicas de las medallas peruanas que han ostentado la imagen de don Hipólito Unanue.
Tabla 1. Características técnicas de las medallas peruanas con la imagen de don Hipólito Unanue.

\begin{tabular}{|c|c|c|c|c|c|}
\hline Motivo & Año & Metal & Diámetro & Peso & Grabador \\
\hline $\begin{array}{l}5^{\circ} \text { Congreso } \\
\text { Latino Americano } \\
\text { y } 6^{\circ} \text { Panamericano } \\
\text { de Medicina - Lima }\end{array}$ & 1913 & $\begin{array}{l}\text { Oro } \\
\text { Plata } \\
\text { Bronce }\end{array}$ & $\begin{array}{l}\text { Sin dato } \\
33 \mathrm{~mm} \\
33 \mathrm{~mm}\end{array}$ & $\begin{array}{l}\text { Sin dato } \\
14,8 \mathrm{~g} \\
14,4 \mathrm{~g}\end{array}$ & $\begin{array}{l}\text { Edmundo } \\
\text { Callirgos }\end{array}$ \\
\hline $\begin{array}{l}\text { Bicentenario } \\
\text { del nacimiento de } \\
\text { Hipólito Unanue }\end{array}$ & 1955 & $\begin{array}{l}\text { Plata } \\
\text { Bronce }\end{array}$ & $\begin{array}{l}40 \mathrm{~mm} \\
40 \mathrm{~mm}\end{array}$ & $\begin{array}{l}29,4 \mathrm{~g} \\
31,4 \mathrm{~g}\end{array}$ & $\begin{array}{l}\text { Armando F. } \\
\text { Pareja } \\
\text { Landeo }\end{array}$ \\
\hline $\begin{array}{l}\text { Medalla } \\
\text { institucional de } \\
\text { la Fundación Instituto } \\
\text { Hipólito Unanue }\end{array}$ & $\begin{array}{l}\text { Sin } \\
\text { año }\end{array}$ & Bronce & $43 n$ & $31,4 \mathrm{~g}$ & pnocido \\
\hline
\end{tabular}

\section{CONDECORACIONES}

\section{Orden Hipólito Unanue}

En 1955, como parte de las celebraciones por el bicentenario del nacimiento de Unanue, el gobierno de Manuel A. Odría instituyó la 'Orden Hipólito Unanue', cuya condecoración la otorgaría el Ministerio de Salud Pública y Asistencia Social a quienes prestaran servicios relevantes en el desarrollo de la Medicina y la salud pública. Dicha Orden fue organizada en cuatro clases: Gran Cruz, Gran Oficial, Comendador y Oficial.

Las condecoraciones fueron acuñadas en la Casa Nacional de Moneda y su diseño fue realizado por el francés Raymond Pelletier, quien grabó el busto del prócer en perfil derecho $3 / 4$, rodeado por un anillo
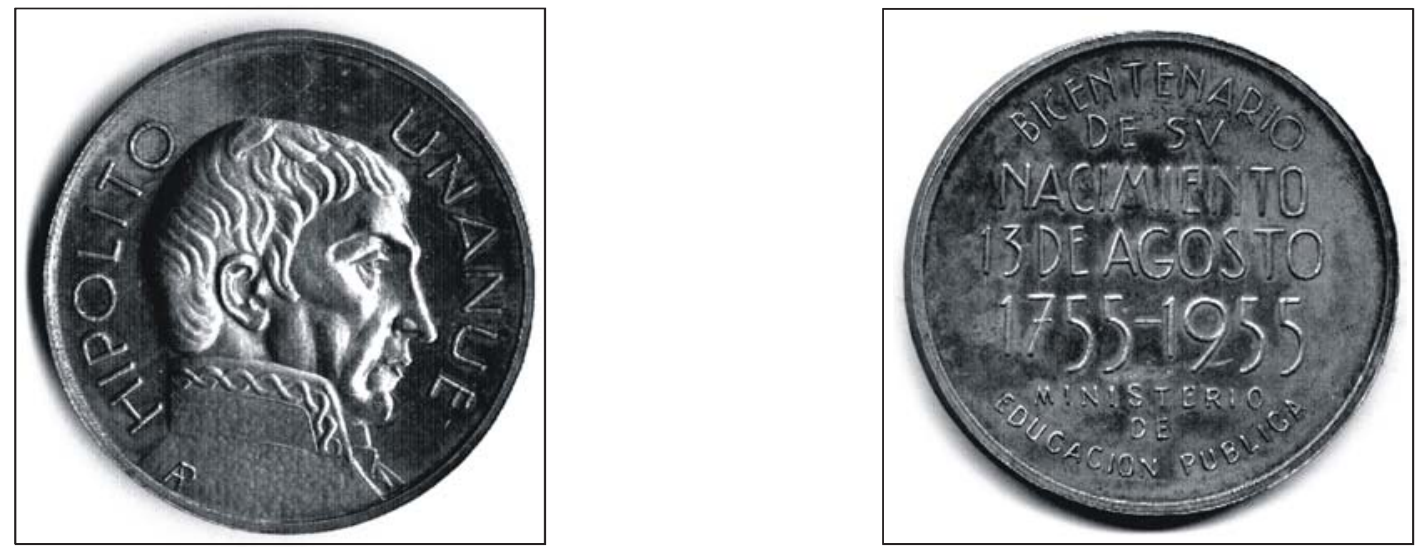

Figura 2. Anverso y reverso de la medalla en conmemoración al bicentenario del nacimiento de Hipólito Unanue. 


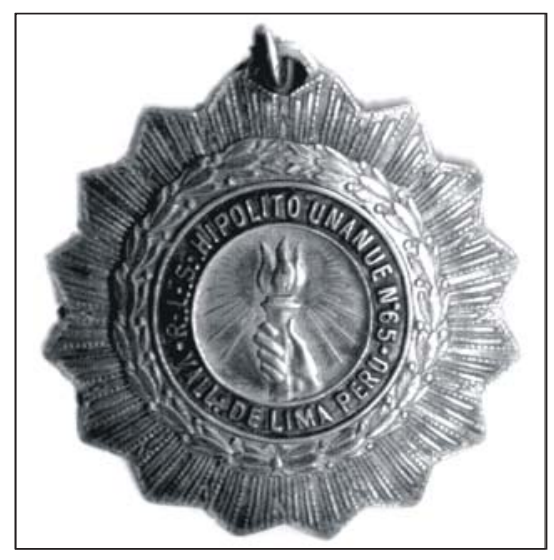

Figura 3. Medalla insignia de la Respetable Logia Simbólica “Hipólito Unanue” Nº 65, fundada en la ciudad de Lima.

esmaltado en color rojo, que contenía la expresión "HIPÓLITO UNANUE". De este conjunto se desprendían cuatro haces esmaltados en color morado, que formaban una cruz y en el lugar donde se unían los haces surgían tres rayos dorados (Figura 6).

Dichas piezas, en todas sus clases, fueron hechas en Plata dorada, con una fineza de 0,925. A diferencia de otros países, donde las condecoraciones son numeradas correlativamente, pieza por pieza, en el Perú no se suele hacer ello, lo que impide determinar a quién perteneció cada una de ellas en particular.

El 27 de agosto de 1957, con motivo del centenario del nacimiento de Carrión, el Presidente

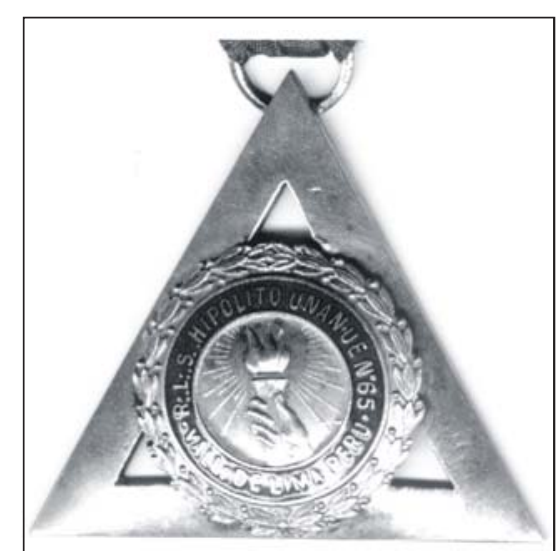

Figura 4. Variante de la medalla insignia de la Respetable Logia Simbólica “Hipólito Unanue” N 65.

Manuel Prado Ugarteche expidió la Resolución Suprema que otorgó "la condecoración de la Orden de Hipólito Unanue en el grado de Gran Cruz, a Daniel Alcides Carrión, debiendo colocarse la insignia en la tumba del Mártir de la Medicina Nacional y entregarse el diploma y banda a la Facultad de Medicina, para incorporarse al Museo Carrión" $\left.{ }^{3}\right)$.

Esta tumba quedó vacía en 1972, cuando los restos de Carrión fueron conducidos al mausoleo erigido en el patio principal del Hospital Dos de Mayo. La condecoración de la tumba original quedó mutilada parcialmente por el pillaje citadino.

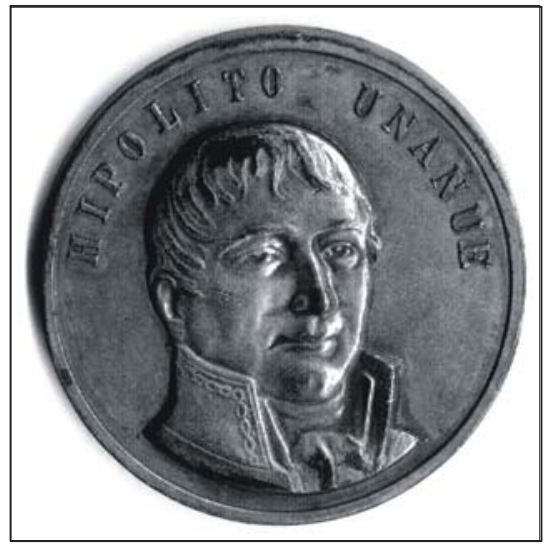

Figura 5. Anverso de la medalla del Instituto Fundación “Hipólito Unanue”.

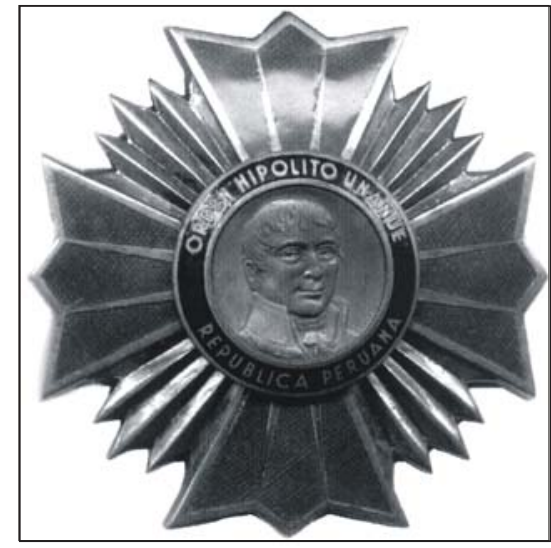

Figura 6. Condecoración de la Orden "Hipólito Unanue". 


\section{Orden Masónica Hipólito Unanue}

La logia 'Hipólito Unanue' instauró la Orden Masónica del mismo nombre, la cual sería concedida a los masones que prestaran servicios eminentes a dicha logia.

Esta condecoración presenta un pequeño busto del prócer en su anverso, dispuesto en medio de un compás y una escuadra entrecruzadas, a la usanza masónica. Este conjunto está rodeado por la inscripción "R.L.S. HIPÓLITO UNANUE 65". En el reverso sólo figura la expresión "ORDEN $A L$ MÉRITO MASÓNICO DE LA R.L.S. HIPÓLITO UNANUE $N^{\circ}$ 65, VALL. DE LIMA - OR. DEL PERÚ" (Orden al Mérito Masónico de la Respetable Logia Simbólica Hipólito Unanue $\mathrm{N}^{\circ} 65$, Valle de Lima, Oriente del Perú) (Figura 7).

Estas piezas fueron hechas en bronce esmaltado, con un diámetro de 80 milímetros, un peso de 82,2 gramos y un grosor de 2 milímetros.

\section{PAPEL MONEDA}

\section{Billete de 100 Soles de Oro}

Hacia fines del primer gobierno de Fernando Belaúnde Ferry, se promulgó la Ley del 23 de febrero de 1968, que autorizaba la emisión de una nueva serie de billetes, cuyas denominaciones iban desde los 5 hasta los 1,000 Soles de Oro.

Estos fueron los primeros billetes en los que aparecieron varios de nuestros personajes, siendo uno

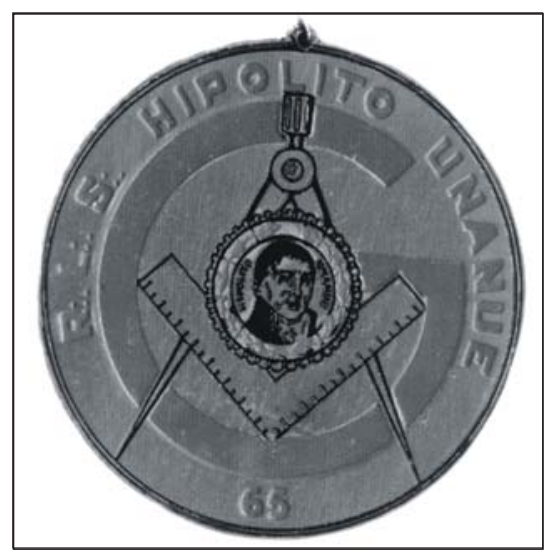

Figura 7. Anverso de Condecoración de la Orden Masónica “Hipólito Unanue”. de ellos el doctor Hipólito Unanue, cuya imagen fue impresa en los de 100 Soles de Oro. El dibujo del prócer fue obra del artista nacional Germán Suárez Vértiz (Figura 8).

El Presidente Belaúnde no llegó a ver en circulación estos billetes durante su gobierno, pues en la madrugada del 3 de octubre de 1968 fue derrocado por el General Juan Velasco Alvarado, en cuyo régimen principiaron a ser utilizados.

El diseño de los billetes de 100 Soles de Oro tenía las siguientes características:

Anverso: En el centro se yergue el Escudo Nacional, a cuya izquierda aparece un grupo de estibadores llevando carga a las naves ancladas y a la derecha el busto de Unanue.

Reverso: Dominado por la iglesia de Santa María de la Caridad, la cual colindaba con el hospital del mismo nombre y al antiguo local de la Universidad de San Marcos; allí se reunió nuestro primer Congreso Constituyente, entre 1822 y 1823 . Los colores dominantes en ambos lados son el verde olivo y el negro.

El gobierno peruano, entre febrero de 1968 y agosto de 1974, encargó la fabricación de ocho series distintas de billetes de 100 Soles de Oro $\left(^{4}\right)$ (Tabla 2).

Tabla 2. Fabricación de las ocho series distintas de billetes de 100 Soles de Oro.

\begin{tabular}{ll}
\hline \multicolumn{1}{c}{ Fecha de emisión } & \multicolumn{1}{c}{ Empresa fabricante } \\
\hline 23 de febrero de 1968 & Thomas de La Rue Company Limited \\
20 de junio de 1969 & Thomas de La Rue Company Limited \\
16 de octubre de 1970 & Thomas de La Rue Company Limited \\
9 de septiembre de 1971 & Thomas de La Rue Company Limited \\
4 de mayo de 1972 & Thomas de La Rue Company Limited \\
24 de mayo de 1973 & Thomas de La Rue Company Limited \\
16 de mayo de 1974 & Thomas de La Rue Company Limited \\
15 de agosto de 1974 & Thomas de La Rue Company Limited \\
\hline
\end{tabular}

\section{Billete de 1'000,000 de Intis}

El 10 de enero de 1985, a fines del segundo gobierno de Belaunde, se expidió la Ley $\mathrm{N}^{\circ} 24064$, por la cual se sustituía al Sol de Oro, nuestra centenaria unidad monetaria, por otra moneda que se denominó Inti, palabra quechua que significa Sol. Este dispositivo establecía que la nueva unidad entraría en vigencia el 1 de febrero de 1985 , con la equivalencia de 1,000 Soles de Oro por cada Inti $\left({ }^{5}\right)$. 


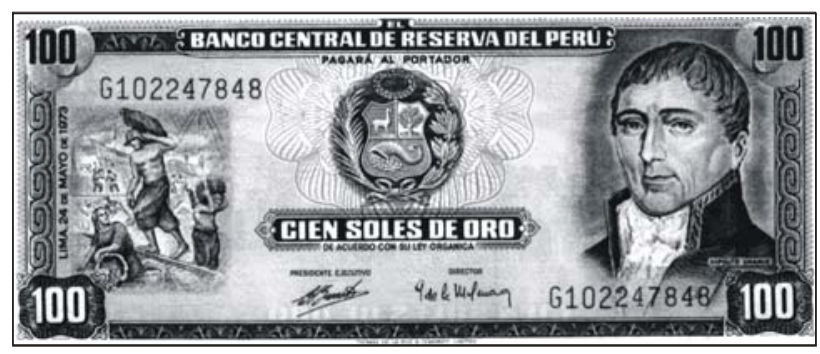

Figura 8. Anverso del Billete de 100 Soles de Oro que presenta la imagen de Hipólito Unanue.

El Inti inició su existencia con un cambio de 6,50 por cada Dólar Americano $\left(^{5}\right)$, pero los avatares económicos sucedidos durante el régimen de Alan García Pérez lo llevaron a una inexorable vorágine de desvalorización, a tal punto que su sucesor, el ingeniero Alberto Fujimori, no tuvo más remedio que extenderle su partida de defunción en diciembre de 1990. En su lugar se introdujo el Nuevo Sol.

El Inti terminó su existencia con un cambio de 800,000 de ellos por cada Dólar Americano $\left(^{5}\right)$. Su devaluación fue aún mayor de la que sufrió nuestro signo monetario en el momento más álgido de la Guerra del Pacífico, es decir durante la ocupación chilena de Lima.

En el breve lapso en que esta moneda fue nuestra unidad monetaria, se emitió el billete de 1'000,000 de Intis, el cual presentó en su anverso la imagen de Hipólito Unanue y en el reverso la fachada de la Facultad de Medicina de San Fernando. El dibujo de nuestro personaje fue el mismo trazado por Germán Suárez Vértiz, aunque con dimensiones algo mayores (Figura 9).

Este billete sólo tuvo dos emisiones, la primera fechada el 5 de enero de 1990 y, la segunda, el 10 de agosto de ese mismo año. En ambos casos, su fabricación fue encargada a la empresa Thomas de La Rue Company Limited $\left({ }^{5}\right)$. Su diseño fue multicolor, pero los tonos predominantes eran el rosa $\mathrm{y}$ el verde.

\section{Epílogo}

Don José Hipólito Unanue y Pavón fue el científico peruano más brillante de finales de la Colonia y principios de la República y, como tal, su memoria ha sido exaltada y recordada en diversas piezas numismáticas. Sin embargo, aún queda una deuda pendiente: su imagen no ha sido grabada en alguna de nuestras monedas, que, por su naturaleza, junto con el papel moneda, son seguramente el medio más eficaz para que llegue a todos los confines del planeta.

Es una pequeña gran deuda de honor que debe ser saldada, sobretodo si consideramos que algunos personajes que han sido incluidos en nuestras monedas, tienen menos lustre y méritos que el padre de la Medicina Peruana.

\section{REFERENCIAS BIBLIOGRÁFICAS}

1. Zapata C. Medallas Conmemorativas del Perú, relación cronológica 1821 - 2000. Lima: Sin pie de imprenta; 2001. p. $101,152$.

2. Paz Soldán C. Himnos a Hipólito Unanue. Lima: Editorial San Marcos; 1960. p. 297-313.

3. Balderrama O. Normas Legales, Rev. Legislación y Jurisprudencia, Tomo XXVII, Número 27, Segundo Trimestre de 1957. Lima: Editorial San Marti S.A.; 1958. p. $44,61,98$.

4. Shafer N. Standard Catalog of World Paper Money. Volumen II. $8^{\circ}$ ed. Illinois: Chester Krause Inc.; 2002. p. 643,645

5. Álvarez R. Las Monedas de Un Inti. Rev Numismática. 1996;43:51-4.

Manuscrito recibido el 15 de noviembre de 2005 y aceptado para publicación el 10 diciembre de 2005.

Correspondencia: Dr. Ricardo Iván Álvarez Carrasco Jirón Antonio Miro Quesada 1088 - Departamento 207

Lima 1, Perú

Correo-e: ralvarez@iemp.gob.pe

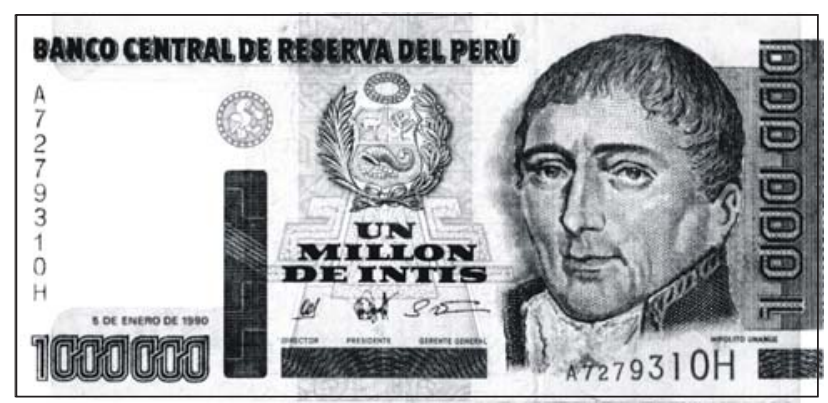

Figura 9. Anverso del Billete de Un Millón de Intis que presenta la imagen de Hipólito Unanue. 